\title{
PENYULUHAN "PERILAKU HIDUP BERSIH SEHAT (PHBS)" DALAM RANGKA PROGRAM TENTARA MANUNGGAL MASUK DESA (TMMD) WILAYAH KODIM 0510 TIGARAKSA, TANGERANG
}

\author{
Shirly Gunawan ${ }^{1}$, Clement Drew ${ }^{2}$, Desintha Cristy Nindi R. ${ }^{3}$, Henyta $^{3}$ dan \\ Karen Permata Sari ${ }^{3}$
}

\author{
${ }^{1}$ Bagian Farmakologi, Universitas Tarumanagara Jakarta \\ Email:shirlyg@fk.untar.ac.id \\ ${ }^{2}$ Bagian Ilmu Kesehatan Masyarakat, Universitas Tarumanagara Jakarta \\ Email: cl3m3ntd@gmail.com \\ ${ }^{3}$ Mahasiswa Program Studi Profesi Kedokteran, Universitas Tarumanagara, Jakarta \\ Email: dearitung22@gmail.com \\ henyta_nita@yahoo.com \\ kenpermata7@gmail.com
}

\begin{abstract}
ABSTRAK
Program Tentara Manunggal Membangun Desa (TMMD) merupakan program terpadu lintas sektoral antara TNI dengan lembaga lainnya dan Pemerintah Daerah yang dilaksanakan secara terintegrasi bersama masyarakat. Kegiatan ini berguna meningkatkan akselerasi kegiatan pembangunan desa, khususnya daerah tertinggal, serta meningkatkan kualitas generasi muda sebagai generasi milenial yang mandiri dan berkarakter kebangsaan. Program TMMD meliputi kegiatan fisik dan non fisik. Kegiatan non fisik TMMD dapat dilakukan melalui penyuluhan di bidang kesehatan, dengan salah satu materinya mengenai Perilaku Hidup Bersih Sehat (PHBS), dengan indikator: pertolongan persalinan oleh tenaga kesehatan, memberi bayi ASI eksklusif, menimbang balita setiap bulan, menggunakan air bersih, mencuci tangan dengan air dan sabun, menggunakan jamban sehat, memberantas jentik di rumah sekali seminggu, makan buah dan sayur setiap hari, melakukan aktivitas fisik setiap hari dan tidak merokok di dalam rumah. PHBS merupakan upaya untuk memberdayakan anggota rumah tangga meningkatkan pengetahuan, kemauan dan kemampuan untuk melaksanakan PHBS serta meningkatkan peran aktif dalam gerakan PHBS di masyarakat. Penyuluhan PHBS kepada warga wilayah Kodim 0510 Tigaraksa, Tangerang dilakukan dalam rangka TMMD ke 102 tahun 2018. Penyuluhan diberikan kepada 80 peserta yang terdiri dari pelajar SMA, Pemuda Karang Taruna, anggota Satuan Polisi Pamong Praja dan masyarakat wilayah setempat. Materi penyuluhan PHBS disampaikan melalui media gambar dan demo secara langsung. Penyuluhan ini memberikan hasil yang baik, terlihat dari hasil evaluasi terhadap materi penyuluhan PHBS, yang dilakukan melalui sesi tanya-jawab. Evaluasi dilakukan dengan menanyakan kembali kepada peserta, beberapa hal penting terkait materi penyuluhan Perilaku Hidup Bersih Sehat dan peserta dapat menjawab dengan benar setiap pertanyaan yang diberikan.
\end{abstract}

Kata kunci: TMMD, kegiatan non fisik, PHBS, Rumah Tangga Sehat

\section{PENDAHULUAN}

Program Tentara Manunggal Membangun Desa (TMMD) merupakan salah satu wujud Operasi Bakti Tentara Nasional Indonesia (TNI), yang merupakan program terpadu lintas sektoral antara TNI dengan Departemen, Lembaga Pemerintah Non Departemen dan Pemerintah Daerah serta komponen bangsa lainnya, termasuk anak-anak muda Indonesia. Kegiatan TMMD merupakan bukti nyata komitmen TNI dalam membangun bangsa dan negara, yang dilaksanakan secara terintegrasi bersama masyarakat (UU RI No. 34, 2004). Kegiatan ini berguna dalam meningkatkan akselerasi kegiatan pembangunan di daerah pedesaan, khususnya 
daerah yang tergolong tertinggal, terisolasi, perbatasan, dan daerah kumuh perkotaan serta daerah lain yang terkena dampak akibat bencana (Subekti, 2018). Selain itu program ini juga bertujuan meningkatkan kapasitas dan kualitas generasi muda agar tumbuh berkembang sebagai generasi milenial yang kompetitif, mandiri dan berkarakter kebangsaan (Supartadi, 2018).

Selain bertujuan untuk membangun fisik, program TMMD juga diharapkan dapat membangun mental, karakter, nasionalisme, patriotisme dan memanfaatkan potensi pemuda desa (Nahrawi, 2018).

Program TMMD merupakan kelanjutan dari program ABRI Masuk Desa (AMD) yang dimulai sejak tahun 1980 di seluruh wilayah Negara Kesatuan Republik Indonesia (NKRI). Kegiatan ini dimaksudkan guna menunjang keberhasilan pembangunan nasional. Sebagai Penanggung Jawab Operasional program ini ialah Kepala Staf Angkatan Darat. Pada tahun 2018 ini, program TMMD merupakan program ke-102, dengan mengambil tema "Manunggal Membangun Karakter Generasi Milenial” (Romadoni 2018).

Dasar hukum yang mendasari penyelenggaraan TMMD ini adalah Undang-Undang Nomor 34 Tahun 2004 tentang Tentara Nasional Indonesia, Undang-undang No. 11 Tahun 2009 tentang Kesejahteraan Sosial, Undang-Undang Pemerintahan Daerah Nomor 32 tahun 2004, Peraturan Presiden RI Nomor 7 Tahun 2005 tentang Rencana Pembangunan Jangka Menengah Nasional Tahun 2005-2009 dan Surat Menteri Dalam Negeri RI tentang Pedoman Penyususan Anggaran APBD untuk Program TMMD, serta Surat Keputusan Menhankam/Pangab tentang Pengesahan Buku Pola dasar Konkritisasi Kemanunggalan ABRI dan Rakyat dan Pola Operasional TNI ABRI Masuk Desa (hukumonline.com 2017).

Program TMMD ini dilaksanakan melalui proses perencanaan yang mengutamakan aspirasi dan kepentingan masyarakat di daerah sasaran dengan menggunakan bottom-up planning system yang dilaksanakan secara komprehensif dan terintegrasi, karena melibatkan semua unsur yang terkait mulai dari tingkat desa hingga kelurahan. Sasaran-sasaran yang dipilih berdasarkan skala prioritas, diteliti dan dipadukan dengan program pemerintah daerah, kemudian dibahas di forum DPRD untuk disahkan menjadi Program Pembangunan Daerah.

TMMD ini melibatkan 33 Departemen dan Lembaga Pemerintah Non Departemen yang secara terpadu memasukkan acuan program masing-masing instansi ke dalam program kegiatan fisik atau non fisik TMMD tersebut. Departemen Dalam Negeri RI ditunjuk sebagai Koordinator Pencapaian Sasaran kegiatan fisik dan Departemen Agama RI sebagai Koordinator Pencapaian Sasaran kegiatan non fisik.

Tujuan kegiatan fisik dalam program TMMD ialah merehabilitasi sarana dan prasarana yang rusak di daerah yang tertimpa bencana alam, meningkatkan sarana prasarana wilayah yang berada di pedesaan berupa infrastruktur, fasilitas umum dan sosial. Sedangkan tujuan kegiatan non fisik yaitu meningkatkan kesadaran berbangsa dan bernegara di kalangan masyarakat, kesadaran bela negara, penegakan hukum, disiplin nasional dan pengetahuan lainnya yang dibutuhkan oleh masyarakat pedesaan, seperti keluarga berencana, kesehatan, pertanian, peternakan, perikanan, dan lain-lain melalui penyuluhan kepada masyarakat tentang bela negara dan ketahanan nasional, atau kegiatan lainnya yang sifatnya memberikan pencerahan dan penguatan jati diri bangsa serta memperkokoh jiwa dan semangat nasionalisme. 


\section{Perilaku Hidup Bersih dan Sehat (PHBS)}

Perilaku Hidup Bersih dan Sehat merupakan salah satu materi penyuluhan yang dibuat oleh Pusat Promosi Kesehatan Departemen Kesehatan RI bagi para kader kesehatan. PHBS adalah perilaku kesehatan yang dilakukan atas kesadaran sehingga anggota keluarga atau keluarga dapat menolong dirinya sendiri di bidang kesehatan dan berperan aktif dalam kegiatan-kegiatan kesehatan di masyarakat (Depkes RI, 2009). PHBS di rumah tangga adalah upaya untuk memberdayakan anggota rumah tangga agar tahu, mau dan mampu melaksanakan perilaku hidup bersih dan sehat serta berperan aktif dalam gerakan kesehatan di masyarakat. PHBS adalah salah satu strategi yang dapat ditempuh untuk menghasilkan kemandirian di bidang kesehatan baik pada masyarakat maupun pada keluarga. Dalam hal ini dibutuhkan komunikasi antara kader dengan keluarga/masyarakat untuk memberikan informasi dan melakukan pendidikan kesehatan (Promkes Pringsewu, 2018). Materi PHBS dapat beragam. Sepuluh indikator PHBS di rumah tangga meliputi: 1. Pertolongan persalinan oleh tenaga kesehatan; 2. Memberi bayi ASI eksklusif; 3. Menimbang balita setiap bulan; 4. Menggunakan air bersih; 5 . Mencuci tangan dengan air dan sabun; 6. Menggunakan jamban sehat; 7. Memberantas jentik di rumah sekali seminggu; 8. Makan buah dan sayur setiap hari; 9. Melakukan aktivitas fisik setiap hari; dan 10. dalam rumah.

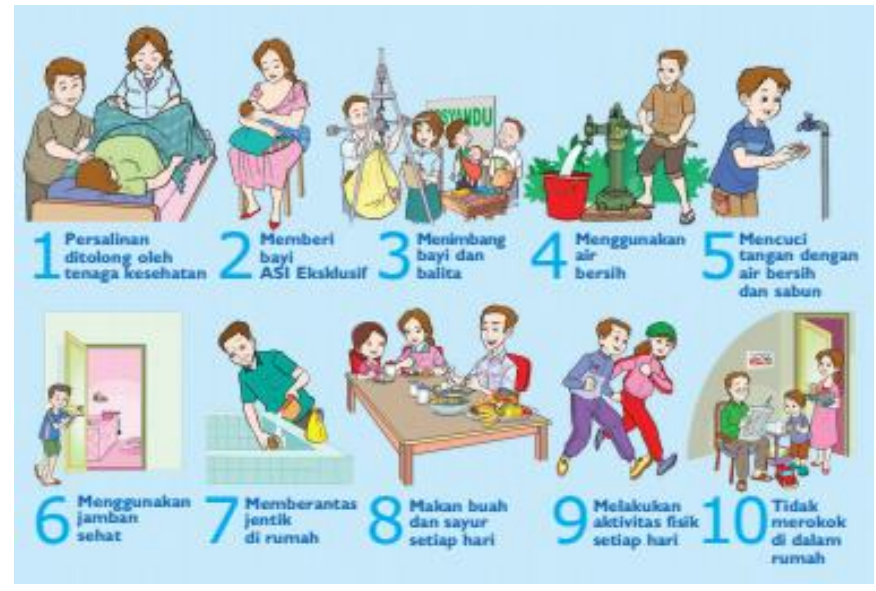

Tidak merokok di

Gambar 1. Sepuluh inidikator PHBS di rumah tangga

PHBS di rumah tangga dilakukan untuk mencapai Rumah Tangga Sehat. Manfaat Rumah Tangga Sehat bagi Rumah Tangga ialah setiap anggota keluarga menjadi sehat dan tidak mudah sakit, anak tumbuh sehat dan cerdas, anggota keluarga giat bekerja, pengeluaran rumah tangga dapat ditujukan untuk memenuhi gizi keluarga, pendidikan dan modal usaha untuk menambah pendapatan keluarga. Manfaat Rumah Tangga Sehat bagi Masyarakat ialah agar masyarakat mampu mengupayakan lingkungan sehat, mencegah dan menanggulangi masalah-masalah kesehatan, memanfaatkan pelayanan kesehatan yang ada serta mampu mengembangkan Upaya Kesehatan Bersumber Masyarakat (UKBM) seperti posyandu, tabungan ibu bersalin, arisan 
jamban dan ambulan desa (Promkes Pringsewu, 2018). Hal-hal penting yang harus dimengerti oleh anggota keluarga mengenai 10 indikator PHBS di rumah tangga seperti yang tercantum dalam tabel 1 .

Tabel 1. Indikator Perilaku Hidup Bersih Sehat (Depkes RI, 2009)

\begin{tabular}{|c|c|c|}
\hline No & Indikator Perilaku Hidup Bersih Sehat & Hal penting yang harus dimengerti \\
\hline 1. & $\begin{array}{l}\text { Pertolongan persalinan oleh tenaga } \\
\text { kesehatan }\end{array}$ & $\begin{array}{l}\text { - Apa yang dimaksud dengan persalinan ditolong } \\
\text { tenaga kesehatan? } \\
\text { - Mengapa setiap persalinan harus ditolong oleh } \\
\text { tenaga kesehatan? } \\
\text { - Apa tanda-tanda persalinan? } \\
\text { - Hal yang harus dilakukan jika ada salah satu tanda } \\
\text { - Apersalinan? }\end{array}$ \\
\hline 2. & Memberi bayi ASI eksklusif & $\begin{array}{l}\text { - Apa yang dimaksud bayi diberi ASI eksklusif? } \\
\text { - Apa yang dimaksud dengan ASI? } \\
\text { - Apa saja keunggulan ASI? } \\
\text { - Kapan dan bagaiman ASI diberikan? } \\
\text { - Bagaimana cara menyusui yang benar? } \\
\text { - Apa manfaat memberikan ASI? Bagi ibu? Bagi } \\
\text { - } \quad \text { bayi? Bagi keluarga? } \\
\text { - Apa yang perlu diperhatikan untuk keberhasilan } \\
\text { - ASI eksklusif? } \\
\text { - } \text { Apakah ibu yang bekerja bisa memberikan ASI } \\
\text { - Bagaimana cara menyimpan ASI di rumah? }\end{array}$ \\
\hline 3. & Menimbang balita setiap bulan & $\begin{array}{l}\text { - Mengapa bayi dan balita perlu ditimbang setiaqp } \\
\text { bulan? } \\
\text { - Kapan dan dimana penimbangan dilakukan? } \\
\text { - Bagaimana mengetahui pertumbuhan dan } \\
\text { perkembangan balita? } \\
\text { - Apa tanda-tanda balita gizi kurang? } \\
\text { - Ada berapa macam gizi buruk pada balita? Apa } \\
\text { - tanda-tandanya? } \\
\text { Apa manfaat penimbangan balita di Posyandu } \\
\text { setiap bulan? }\end{array}$ \\
\hline 4. & Menggunakan air bersih & $\begin{array}{l}\text { - Mengapa harus menggunakan air bersih? } \\
\text { - Apa syarat air bersih? } \\
\text { - Apa manfaat menggunakan air bersih? } \\
\text { - Dimana memperoleh sumber air bersih? } \\
\text { - Bagaimana menjaga kebersihan sumber air bersih? } \\
\text { - Mengapa air bersih harus dimasak mendidih bila } \\
\text { ingin diminum? }\end{array}$ \\
\hline
\end{tabular}




\begin{tabular}{|c|c|c|}
\hline & & $\begin{array}{l}\text { - Kapan saja harus mencuci tangan? } \\
\text { - Apa manfaat mencuci tangan? } \\
\text { - Bagaimana cara mencuci tangan yang benar? }\end{array}$ \\
\hline 6. & Menggunakan jamban sehat & $\begin{array}{l}\text { - Apa itu jamban? } \\
\text { - Apa saja jenis jamban? } \\
\text { - Bagaimana memilih jenis jamban? } \\
\text { - Siapa yang diharapkan menggunakan jamban? } \\
\text { - } \text { Apengapa harus menggunakan jamban? } \\
\text { - Bagaimana cara memelihara jamban sehat? }\end{array}$ \\
\hline 7. & $\begin{array}{l}\text { Memberantas jentik di rumah sekali } \\
\text { seminggu }\end{array}$ & $\begin{array}{l}\text { - Mengapa harus memberantas jentik di rumah? } \\
\text { - Apa itu Rumah bebas jentik? } \\
\text { - Apa itu Pemeriksaan Jentik Berkala (PJB) } \\
\text { - Siapa yang melakukan Pemeriksaan Jentik } \\
\text { - Berkala? } \\
\text { - Apa yang perlu dilakukan agar rumah bebas jentik? } \\
\text { - Apa manfaat rumah bebas jentik? }\end{array}$ \\
\hline & Makan buah dan sayur setiap hari & $\begin{array}{l}\text { - Siapa yang diharapkan makan buah dan sayur? } \\
\text { - Mengapa kita harus memakan buah dan sayur? } \\
\text { - Apa manfaat vitamin yang ada di dalam sayur dan } \\
\text { buah? } \\
\text { - Apa manfaat serat yang ada di dalam buah dan } \\
\text { - Sayur? } \\
\text { - Berapa banyak sayur dan buah dalam sehari harus } \\
\text { - Sita makan? } \\
\text { - Bagar dan buah seperti apa yang bagus kita makan? } \\
\text { merusak atau mengurangi kandungan gizinya? }\end{array}$ \\
\hline & Melakukan aktivitas fisik setiap hari & $\begin{array}{l}\text { - Siapa yang diharapkan melakukan aktivitas fisik? } \\
\text { - Apa itu aktivitas fisik? } \\
\text { - Apa jenis aktivitas fisik yang dapat dilakukan? } \\
\text { - Berapa lama seseorang perlu melakukan aktivitas } \\
\text { fisik setiap hari? } \\
\text { - Bagaimana cara melakukan aktivitas fisik yang } \\
\text { benar? } \\
\text { - Apa keuntungan melakukan aktivitas fisik secara } \\
\text { teratur? }\end{array}$ \\
\hline 10. & Tidak merokok di dalam rumah & $\begin{array}{l}\text { - Siapa yang diharapkan tidak merokok di dalam } \\
\text { - } \text { rumah? } \\
\text { - Apngapa harus tidak merokok? } \\
\text { - Apa bahaya perokok aktif dan perokok pasif? } \\
\text { - Bagaimana cara berhenti merokok? }\end{array}$ \\
\hline
\end{tabular}

Topik PHBS dipilih menjadi materi penyuluhan dalam kegiatan TMMD ke-102 tahun 2018 ini karena topik ini merupakan salah satu materi penyuluhan yang penting dan rutin diberikan oleh kader kesehatan wilayah Tangerang. Dalam Renstra Dinkes 2013-2018, target persentase 
Rumah Tangga yang telah ber-PHBS sebesar 63\% pada tahun 2016. Data Bidang Promosi Kesehatan Kabupaten Tangerang tahun 2016, menunjukkan kegiatan PHBS tahun 2016 di wilayah Tigaraksa baru mencapai 44\%, sehingga program PHBS ini masih perlu terus disosialisasikan (Dinkes Kabupaten Tangerang, 2016).

\section{METODE PELAKSANAAN}

Kegiatan pengabdian kepada masyarakat (PKM) ini dilakukan dalam rangka mendukung program TMMD ke-102 tahun 2018 yang dimulai pada tanggal 9 Juli hingga 16 Agustus 2018. Kegiatan ini selain melibatkan prajurit TNI-Polri, juga didukung kementerian/lembaga, khususnya pemerintah daerah setempat, dengan melibatkan kerja sama dengan institusi pendidikan dan masyarakat wilayah setempat. Pada kesempatan ini, Universitas Tarumanagara mengemban tugas mendukung kegiatan non fisik berupa penyuluhan yang meliputi 4 topik utama, yaitu sebagai berikut: Kenakalan Remaja, Koperasi dan UKM, Kesehatan, Robot dan UKM. Untuk topik Kesehatan yang ditugaskan kepada Fakultas Kedokteran Universitas Tarumanagara, salah satu topik yang diangkat sebagai materi penyuluhan adalah Perilaku Hidup Bersih dan Sehat. Kegiatan PKM ini dilaksanakan pada tanggal 12 Juli 2018 dengan mengambil tempat di Aula Kecamatan Balaraja, Tangerang. Sebagai peserta dari kegiatan ini, hadir kurang lebih 80 peserta yang terdiri dari pelajar SMA, Pemuda Karang Taruna, anggota Satuan Polisi Pamong Praja (Satpol PP) dan masyarakat wilayah setempat. Acara penyuluhan tersebut diawali dengan pembukaan oleh Komandan Rayon Militer (Danramil) Balaraja, Kapten Arm. Hari Subagiyono dan Bapak Camat Balaraja Dra. Mas Yoyon, S.H. Hadir pula pada kesempatan itu para wakil dari berbagai institusi seperti Kepala Seksi Ketentraman dan Ketertiban (Kasi Trantib) Bapak Subagya, Wakil dari Polres Tangerang, Iptu Rastiga dan Iptu Winarni serta wakil dari Kodam, Kapten ARH Aris Supriyadi dan Lettu Infantri Wellman Silitonga.
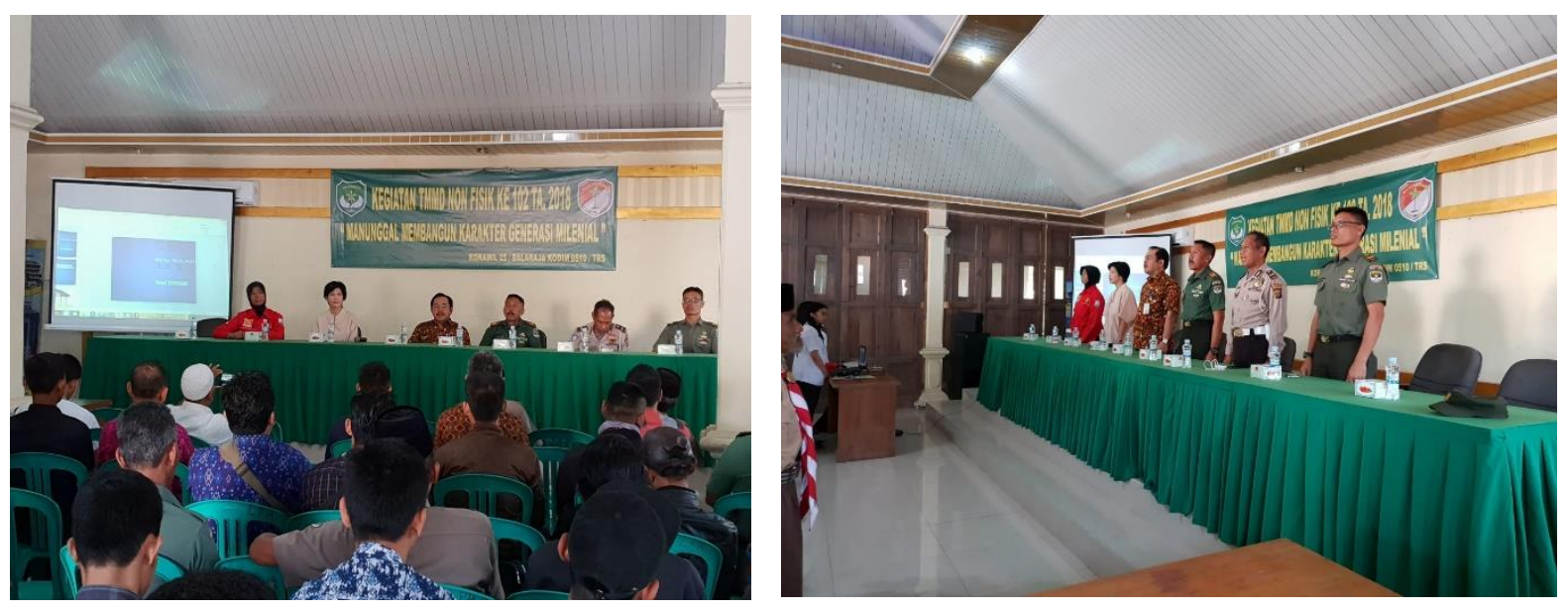

Gambar $3 \& 4$. Berbagai unsur masyarakat berpartisipasi dalam mendukung program TMMD 


\section{HASIL DAN PEMBAHASAN}

Dalam kegiatan TMMD ini, materi tentang 10 Perilaku Hidup Bersih Sehat ini disampaikan melalui media gambar dan demo secara langsung (misal pada PHBS-mencuci tangan) sehingga cepat dipahami dan mudah untuk diingat oleh para peserta.
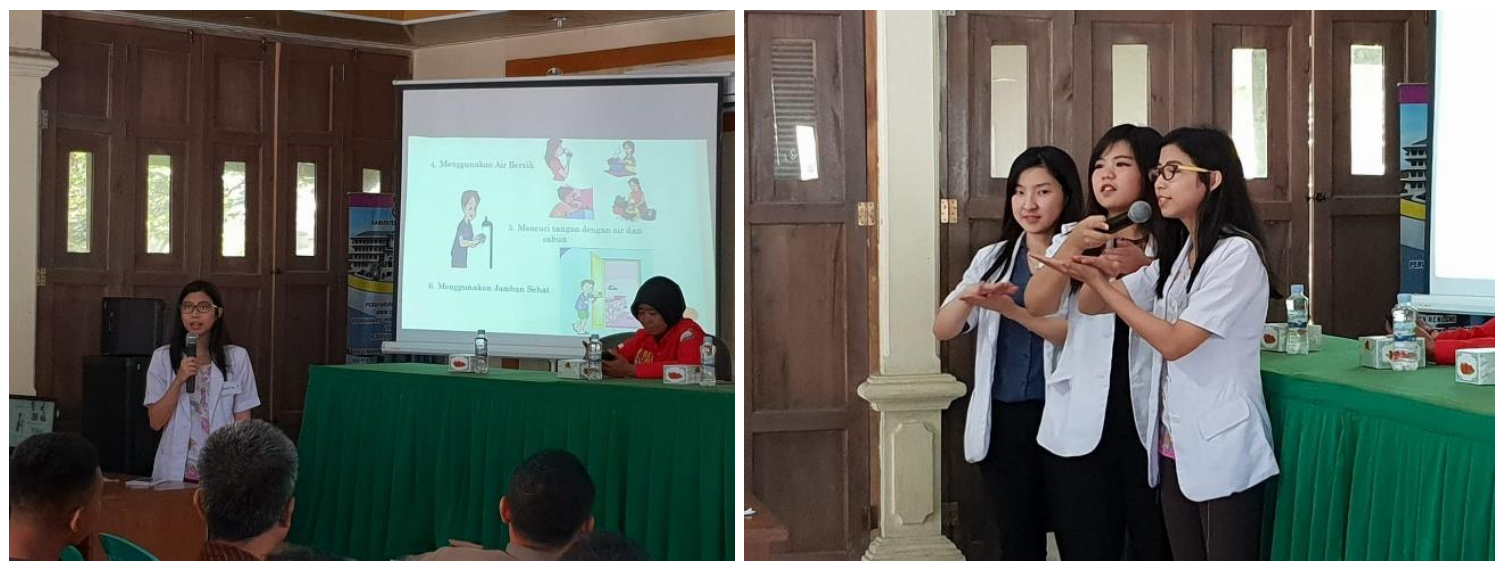

Gambar 4 \& 5. Tim penyuluh memaparkan tentang 10 indikator PHBS dan mendemonstrasikan cara mencuci tangan yang benar

Penyuluh menyampaikan hal-hal penting dalam tiap indikator Perilaku Hidup Bersih Sehat, seperti yang tercantum dalam tabel 1. Setelah selesai pemaparan seluruh materi PHBS, dilakukan sesi tanya-jawab dengan nara sumber dan dilakukan kuis untuk menguji kemampuan daya tangkap peserta terhadap materi tentang 10 indikator PHBS. Peserta tampak antusias dalam menjawab semua pertanyaan yang diberikan serta aktif untuk bertanya hal-hal yang masih kurang dimengerti. Pertanyaan kuis terlampir dalam tabel 2.

Tabel 2. Pertanyaan Kuis

\begin{tabular}{lll}
\hline No. & Indikator PHBS & Pertanyaan Kuis \\
\hline 1. & Pertolongan persalinan oleh tenaga kesehatan & Apakah tanda-tanda persalinan? \\
2. & Memberi bayi ASI eksklusif & Apa yang dimaksud dengan ASI eksklusif? \\
& & Apa keunggulan ASI? \\
3. & Menimbang balita setiap bulan & Kapan harus dilakukan penimbangan pada balita? \\
& & Dimana bisa dilakukan penimbangan ini? \\
4. & Menggunakan air bersih & Apa syarat air bersih? \\
5. & Mencuci tangan dengan air dan sabun & $\begin{array}{l}\text { Peserta diminta mendemonstrasikan cara mencuci } \\
\text { tangan yang benar }\end{array}$ \\
6. & Menggunakan jamban sehat & Bagaimana cara memelihara jamban sehat? \\
7. & Memberantas jentik di rumah sekali seminggu & Apa yang harus dilakukan agar rumah bebas jentik? \\
& & Apa yang dimaksud dengan prinsip 3M (Menguras, \\
& & Menutup, Mengubur)? \\
8. & Makan buah dan sayur setiap hari & $\begin{array}{l}\text { Berapa banyak sayur dan buah yang harus dikonsumsi } \\
\text { setiap hari? }\end{array}$ \\
9. & Melakukan aktivitas fisik setiap hari & $\begin{array}{l}\text { Berapa lama seseorang perlu melakukan aktivitas } \\
\text { fisik setiap hari? } \\
\text { Mengapa tidak boleh merokok? Apa bahaya }\end{array}$ \\
10. & Tidak merokok di dalam rumah. & $\begin{array}{l}\text { merokok? } \\
\end{array}$
\end{tabular}


Seluruh pertanyaan kuis yang ditanyakan dapat dijawab dengan benar oleh peserta, baik secara individual maupun kolektif. Pada saat diminta demonstrasi mencuci tangan, seorang peserta maju untuk mendemonstrasikan. Peserta tersebut sempat lupa beberapa langkah mencuci tangan yang benar, sehingga penyuluh mengulang kembali langkahlangkah yang benar, diikuti oleh peserta tersebut dan peserta lainnya. Ada keterbatasan waktu dalam sesi kuis sehingga maksimal hanya 1 pertanyaan yang dilontarkan kepada peserta, karena acara TMMD ini juga diisi dengan

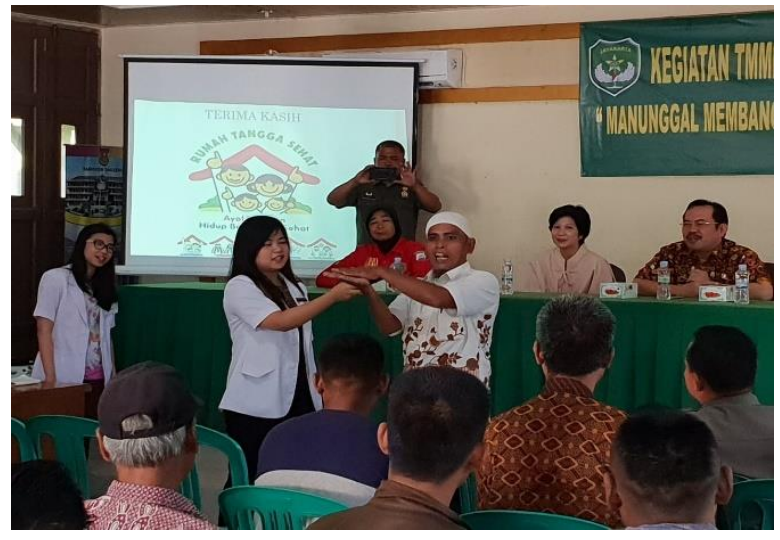
penyuluhan topik lain.

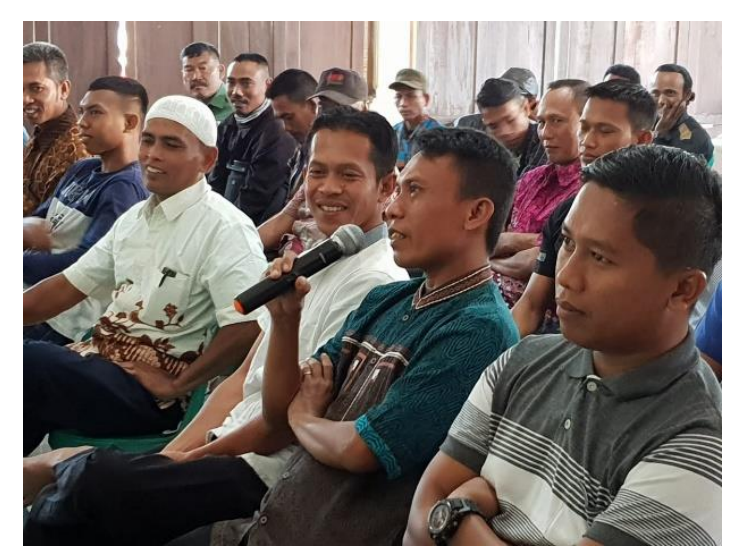

Gambar 6. Peserta tampak aktif dalam menjawab kuis
Gambar 7. Peserta sedang mendemonstrasikan PHBS mencuci tangan

\section{KESIMPULAN DAN SARAN}

Pelaksanaan program TMMD ke-102 non fisik tahun 2018 untuk wilayah Kodim 0510 Tigaraksa, khususnya untuk program kesehatan dapat terlaksana dengan baik. Program terpadu lintas sektoral ini dapat melibatkan kerja sama yang terintegrasi dengan baik dari berbagai pihak serta melibatkan partisipasi aktif masyarakat setempat. Masukan untuk pelaksanaan kegiatan penyuluhan serupa dalam kesempatan mendatang ialah melakukan kegiatan pretest 
dan postest bagi seluruh peserta sehingga akan diperoleh gambaran hasil evaluasi secara kuantitatif, yang lebih representatif dalam menunjukkan keberhasilan program penyuluhan. Selain itu kegiatan penyuluhan PHBS ini bisa dilakukan secara lebih terfokus pada kelompokkelompok tertentu dengan topik yang sesuai, misal cara mencuci tangan yang benar pada kelompok siswa SD, atau penyuluhan tentang pentingnya ASI eksklusif pada ibu-ibu hamil. Namun secara umum, program TMMD non fisik telah terlaksana sesuai sasaran dalam rangka meningkatkan kesadaran masyarakat di bidang kesehatan, khususnya dalam membina perilaku hidup bersih sehat di rumah tangga.

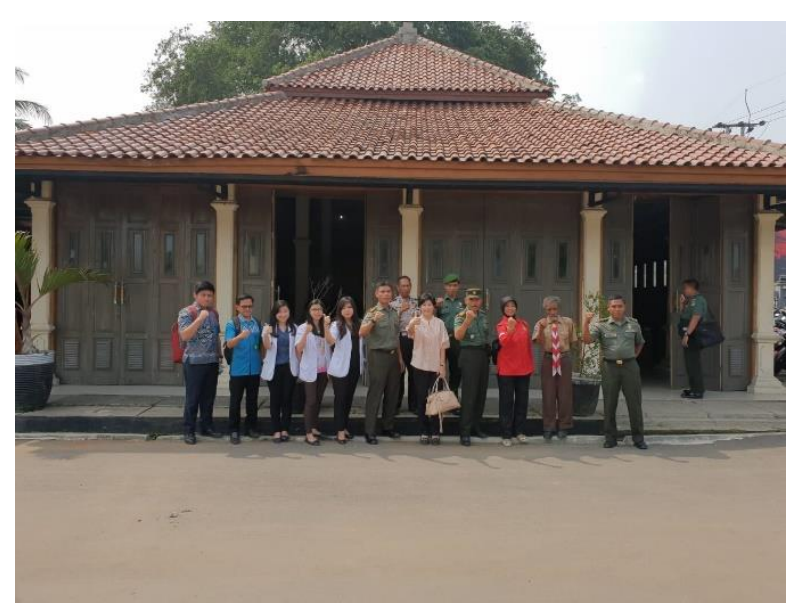

Gambar 9. Seluruh tim yang terlibat dalam TMMD ke-102 tahun 2018 di wilayah Kodim 0510 Tigaraksa

\section{Ucapan Terima Kasih (Acknowledgement)}

Terima kasih sebesar-besarnya kepada seluruh pihak yang terlibat dalam TMMD ke-102 tahun 2018:

- Kodim 0510 Tigaraksa, Tangerang

- Koramil Balaraja, Tangerang

- Kecamatan Balaraja, Tangerang

- Puskesmas Balaraja, Tangerang

- Polres Tangerang

- DPPM Universitas Tarumanagara

- UPPM Fakultas Kedokteran Universitas Tarumanagara

\section{REFERENSI}

Departemen Kesehatan RI (2009). Rumah Tangga Sehat dengan Perilaku Hidup Bersih dan Sehat. Diperoleh tanggal 20 Agustus 2018, dari http://promkes.depkes.go.id/wpcontent/uploads/pdf/buku_pedoman/booklet\%20phbs\%20rumah\%20tangga.pdf

Dinkes Kabupaten Tangerang (2016). Profil Kesehatan Kabupaten Tangerang. Diperoleh tanggal 12 September 2018, dari http://dinkes.tangerangkab.go.id/wpcontent/files/Profil_2016_New.pdf 
Hukumonline.com (2017). Program Tentara Manunggal Membangun Desa. https:// http://www.hukumonline.com/klinik/detail/lt592b7e0813a80/program-tentara-manunggalmembangun-desa-tmmd

Nahrawi (2018). Menpora harap Program TMMD Bangun Potensi Pemuda Desa. https://www.merdeka.com/peristiwa/menpora-harap-program-tentara-manunggal-membangundesa-bangun-potensi-pemuda-desa.html

Promkes Pringsewu (2018). Perilaku Hidup Bersih Sehat. Diperoleh tanggal 12 September 2018, dari https://phbspringsewu.wordpress.com/pengertian-phbs/

Romadoni M (2018). Upacara Pembukaan TMMD Reguler Ke-102 Tahun 2018: Manunggal Membangun Karakter Generasi Milenial. Diperoleh tanggal 20 Agustus 2018, dari http:// surabaya.tribunnews.com/2018/07/10/upacara-pembukaan-tmmd-reguler-ke-102-tahun2018-manunggal-membangun-karakter-generasi-milenial

Subekti TR (2018). Program TMMD 2018, TNI Jalin Sinergi dengan Kemendikbud. Diperoleh tanggal 20 Agustus 2018, dari http:// http://www.suarapemredkalbar.com/berita/ponticity/2018/03/14/program-tentara-manunggalmasuk-desa-2018-tni-jalin-sinergi-dengan-kemendikbud

Supartadi (2018). TMMD Membangun Potensi Pemuda Desa. Diperoleh tanggal 20 Agustus 2018, dari http://www.merdeka.com/peristiwa/menpora-harap-program-tentara-manunggalmembangun-desa-bangun-potensi-pemuda-desa.html

Undang-Undang Republik Indonesia No. 34 tahun 2004 tentang Tentara Nasional Indonesia. $\begin{array}{llll}\text { Diperoleh } & \text { tanggal } & 20 & \text { Agustus }\end{array}$ http://ditjenpp.kemenkumham.go.id/arsip/ln/2004/uu34-2004.pdf 